\title{
Interviews
}

\section{The emergence of the new digital agency - Interview with Dennis Pannuto of Aha! Insight Technology}

\begin{abstract}
Dennis Pannuto
is the president/founder of Aha! Insight Technology, Inc. (ahainsight.com). Aha! delivers innovative digital media solutions and interactive technologies that transform companies by maximizing ROI and establishing market leaders. Aha! also provides Fortune 1000 companies and entrepreneurs with C-suite strategic guidance across their technology enterprise to achieve measurable results.

Before founding Aha!, Dennis was the Chief Information Officer at BBDO Worldwide, the third largest global advertising network. In 2003 and 2004, he led BBDO to be recognized by InformationWeek, the leading weekly trade publication in technology, as one of the top 500 IT innovators. This honor was unheralded in BBDO's history. Dennis also enjoyed successful years at Golden Books Family Entertainment in various positions and ultimately served as their Chief Information Officer. He is considered one of the leading international authorities in the design of digital media/workflow solutions and is frequently invited to speak, teach, write and participate in major events.
\end{abstract}

Keywords: Y generation, global brand, communication platform, experiential marketing

Abstract How important is it for a CMO to define and own a services framework for a digital supply chain? In the 1990s, we knew that the future of IT was about specialists closely aligned with the business. Now, the CMO and Chief Information Officer (CIO) roles are merging. Their role is to start dynamically managing campaigns. Michael Moon interviews Dennis Pannuto of Aha! Insight Technology to gain insight into these industry shifts.

Journal of Digital Asset Management (2008) 4, 127-137. doi:10.1057/dam.2008.20

MM: We're here with Dennis Pannuto of Aha! Insight Technology.

Dennis, please give us some background in terms of your career and current focus.

DP: Sure. I started my own company in 2006:

Aha! Insight Technology. The focus of this firm is to basically work with Fortune 1000s and entrepreneurs to develop business strategies and technology roadmaps focused on innovative digital media solutions and interactive technologies. We also provide Fortune 1000 companies and entrepreneurs with C-suite strategic guidance across their technology enterprise to achieve measurable results.

Before that, I was CIO for BBDO Worldwide — the third-largest global advertising network. I was there for five years and had a good amount of success.

Before that, I was the CIO for Golden Books Family Entertainment, which was at one time the largest North American children's publishing company. We also had a very large, extensive library of films and video $-3,000$ films and videos that we distributed.

I spent a lot of time - about 18 years - in corporate technology and multi-media publishing. I've done it all. I came up the hard way. I've pretty much done everything from implementing financial systems, data warehouses, warehouse management systems, manufacturing systems and building out data centers to managing and supporting multi-media publishing; a big part of supply chain has been in my path. So I'm very much aware of the principles of good supply chain management. I've adapted that to how I develop and implement most of my digital solutions. The digital asset supply chain is at the center of every company and group that is involved in the production and distribution of digital content, whether or not they are a traditional supply chain company. 
MM: You might be what would be classed as a master-class practitioner for digital supply chains.

Let me start with a story. I have a good friend and business partner in another firm who has a 12-year old daughter. Her name's Shannon. A year ago, Gary and Shannon were going to Comp USA or Best Buy or whatever it was to get her mom, Anne, an iPod.

As they were driving down the road, Gary turns to Shannon and says, "Hey. Do you suppose Mom would like an MP3 player?" Because it's got more features.

Shannon, being 12 years old and somewhat precocious, said, "No, Dad. Mom wants an iPod."

Gary says, "Well, how do you know?" Shannon said, "Well, she's always borrowing mine."

Gary thought, "That's not a bad answer." He said, "What do you think about this new Microsoft Zoom?" That was being touted a lot in advertising.

Shannon said, "Dad - you don't know anything about brands."

Now Gary's a PhD. Organizational development. Harvard Business School. Serial entrepreneur. Started five or six companies. He was president and CEO of a division of Phillips.

Gary turns to his daughter and says, "What about brands don't I know?” She said, "Dad everyone knows that if you have to advertise it, something's wrong with it."

Gary goes, "Hmm. Well, how do you find out about stuff?" She said, "Well, I go online and check out some forums and blogs. If they speak about it being good, then I talk to my girlfriends. If they've heard about it, I know it's good."

He goes, "Hmm." Then Gary adds to this anecdote or story that it's the moral obligation - in his opinion - for every teenage daughter to have at least two annoying hobbies.

It turns out that Shannon's hobbies are fencing and drumming. So there's a drum set downstairs next to the bedroom and the media room. Gary says that every day he has to go downstairs when she's drumming away and say, "Hey. Knock it off! Quiet!"

So it came that time of day and Gary goes downstairs. There's Shannon on her drum set. She's got her little iPod and speakers. Through the speakerphone is coming guitar music.
Gary says, "Hey! Whatcha doin'?” Shannon says, "I'm playing with Nicole!" Gary, being the concerned father that he is, says, "Do we know Nicole from school?" "Oh, no!" Shannon says. "She lives in Oregon."

"Well, how did we find Nicole?" "Oh, I found her on the web. We're starting a band."

I used these vignettes about Shannon to describe something that has fundamentally changed in consumer markets. And to a lesser but a meaningful extent in B2B markets.

You and I have two hands. We log on, go to the web, do whatever we're going to do and log off. Shannon never logs off. She's on 24/7 with her mobile connection and Twitter and all that kind of stuff. She has completely internalized the web as part of her social network.

In addition to that, she doesn't have two hands. She has three. Her third one is all digital. Quite literally, that's how she navigates and touches and manipulates that digital world that is always with her wherever she goes.

The question I put to you, Dennis, is this: what constitutes a digital third hand strategy for marketers today?

DP: Well, that's a reality that is at the forefront right now of a cultural change. It's shifting all demographics. It's changing all age groups. It's not just limited to the "Y" generation, but is pushing its way through all of the demographics and market categories today.

The reality is that marketers today whether you're a Fortune 100 company or a consumer products goods company or an internet startup - you have to have an attuned sensitivity to the reality that there is a digital space out there that's all about engaging a selfdirected buyer and a self-directed individual.

Your brand has to operate effectively in that space. That breaks down barriers and walls that just did not exist in the past.

Much of the work I do today is addressing these dynamics. Whether they're a Fortune 100 or whether they're a startup internet company, they've got to have an internet marketing strategy that has a very smart and well-balanced social-media and social-networking component to it. Otherwise their brand will suffer.

MM: Have I shared with you our brandinteraction and engagement model?

In this particular model, I start to frame three or four issues as they relate to this strategy. 
Generally, most customers or consumers or people in the web sphere or cloud basically fall into a category called "Unknown" to a seller. These would be the anonymous visitors of a website.

The "Knowns" convert into a "Known" where I've dropped a cookie on the web visitor. I've now gotten some behavioral activity data associated with him - maybe even an e-mail address and some basic things. I begin to interact and provision various interactions with this consumer.

The next major conversion in an engagement strategy is going from "known" to "profile." That's when I've gotten some information from them to then start to correlate with these compiled databases from Axiom or Epsilon or Merkle. I can start to develop a richer demographic and psychographic profile of this visitor, who's now profiled.

As I start to engage them in personal interactions, the next major conversion is when they move into being a subscriber. At that point, a marketer can start creating highly personalized, customized web interactions as a function of wrapping fluid web properties and brand interactions around a highly personalized digital persona.

Finally, the last conversion often entails becoming a member of a loyalty program. Oftentimes, this entails a much higher level of collaboration than just a message board or a web board and stuff. Does that progression make sense? If so, what are some of the challenges in thinking through a strategy for that?

DP: I think that progression makes sense in many business models. I think there are obvious deviations from that in some cases. But yes, as far as developing the strategy, it's taking all of those interactions from start to finish and being very sensitive to how people in the digital space will react to those.

Today, it's all about conversation. Really, it's about creating or engaging in those conversations on the web. Depending on whatever segment of that lifecycle you're going through, it's all about participating in some type of conversation that will take that consumer or that person and make them part of your community - and then keep them there.

Keeping them not only so there's loyalty, but also now they become a marketing voice for the brand. They're actually marketing by communicating their experience in their communities. They're becoming a marketing vehicle within the community that you're trying to create. And it's their voice that matters more than the brand's voice in many instances.

Not only do they create conversations about brands, they are now a critical part of directing that transaction, as well as directing the community in many instances. There's a pride factor; they want to feel good about their contribution.

Look at some of the simple models out there: Skype, Linkedin and Facebook. You become part of these communities and all of a sudden people start reaching out to you - you get connected with others, reviews get written. In those examples "your brand" is more controlled because you only connect with people you want to and you moderate what is said about you to a large degree. Not so easy with Fortune 1000s in cyberspace.

MM:You introduced this notion of a conversation with the consumer.

I'd like to come back and revisit that. From a brand marketer's perspective, conversations are a great kind of meet-and-greet, but the real art of marketing to someone of Shannon's generation is not so much a conversation as it is persuasion and argumentation.

DP: If we're going to talk about Shannon - if she's the example there - I don't think Shannon thinks about all of those things consciously.

She's going to react to the experience that she has. She's also going to react to the experience that other people have. That's part of building that community.

That's where I say that in the early part of the value chain that you're trying to create or that a marketer's trying to create - especially if they're trying to sell to Shannon - it's got to be something that immediately engages them. That may be through conversation.

MM: I agree with you that the initial courtship is going to be very conversational and undirected.

DP: Right. In some cases. In many cases. A lot of her conversations are happening digitally.

They're not happening in the traditional way: in the schoolyard or at some kind of after-school 
activity. It's happening over the web and it's global.

So I think a marketer - if we're still using Shannon as an example - has to make you feel that way. If they're trying to promote their product, it has to be immediately engaging. It has to be honest. And in some way, it has to get them in there right away.

They've got to "taste" something. They've got to "touch" something.

For example, let's look at things like Webkinz. There's an example of a traditional product - a brick-and-mortar product. A stuffed animal that now has become the hook into a whole digital world that's engaging young children.

To get them as part of that value chain you must engage them with something that they're attracted to. It's not only the plush toy. It's the idea that they can go and build their own world and interact with others.

MM: Take us through the Webkinz experience. DP: I've got three kids and about over 20 Webkinz at my house. I think the whole Webkinz experience is brilliant. And I'm sensitive to it. When I was at Golden Books working in the children's entertainment market we played with this idea - this was back in the 1990 's. We tried to come up with some way to get the internet involved with some kind of interaction, and to build a market there with our products.

We had books. We had videos. We had toys and games. One example of a product we developed before its time was FindItQuick.com. FindItQuick.com was a subject specific book, like Astronomy or Dinosaurs, that you bought in a bookstore. There was a website where you had to type in a code and become part of that community. There were links inside the book that would take you to the main site and various websites to get new content and updates, engage in activities, play games and interact within the community. The timing was off. It didn't work as we would have liked. So I get the whole Webkinz phenomenon.

When I saw Webkinz come to market, right away I thought, “They've got it. They've got it, and it's going to boom." That's exactly what happened.

What's really unique about the Webkinz experience - and why it works, in my opinion
— is not only because kids want to build their own world, but also because it addresses a very fundamental and social dynamic that's part of every human being. That is the desire and the need to communicate with other people. And to socialize with them.

Amazingly, I'll come home and see my daughter who's nine years old hogging up the house phone, on speaker with her friends. threeway calls while they're in Webkinz. They're going to the different rooms and chatting. They're basically building their world.

They're not only building their world, but also they're able to share that world with each other. They're out there gaining virtual money for this, so they can build and buy more materials for their world.

MM: So what does Webkinz involve? DP: You basically buy a plush toy. The stuffed animal has a number on it - a unique identifier. You get onto Webkinz.com and register it. Then all of a sudden, you've got this identity. You go in and start to build your world. You gain virtual money to be able to buy things by engaging in different activities.

MM: So the idea is that there are these educational activities appropriate to a six-yearold or an eight-year-old or a ten-year-old. When they play the game, they get a kind of currency or points of some sort.

They use that to then buy food and other sorts of things for the digital version of their plush toy. Is that correct? If, for some reason, they don't feed their digital Webkinz, they start to look like sad, poor starving puppies.

DP: That's right.

MM: That elicits from them, "Oh, my Webkinz needs some food!" That, then, is the empathetic impulse to go do stuff to earn points, to buy foods and to keep the cycle of life going. DP: That's absolutely correct. Very similar to Tamagotchi Town. Yes.

MM: Then what happens is that if you want to have another digital Webkinz, you've got to go get the plush toy in the store. Is that correct? DP: Yes.

MM: What's interesting about this from a social dynamic perspective is that the plush toy becomes a persistent messaging object of the online - and otherwise intangible destination. The question that marketers would abstract from this is "What are the plush toy 
equivalents for the online experience that we want to give our customers?"

DP: Exactly.

And Apple is a perfect example of getting it right. You've got your iPod connected to our iTunes. Right? You're connected to both worlds. You've created that physical symbol. That physical icon.

You've got that physical connection and then you've got your digital world. Same thing if you go to my kids' rooms. Each one of them in their rooms has lined up all of their Webkinz. They will play with them physically if they're not online with them. They do that. It's kind of like playing house in the 21 st century.

MM: The question then is, as a former CIO of one of the largest advertising agencies in the nation - who was intimately involved in marketing and branding products and services - what comes to mind as the Webkinz equivalent for an executive?

DP: That's the key. That's the silver bullet for most brands. Find that, and you've got it.

I just recently worked with a client - a very well-known brand. For them, we found that their content was basically their "plush toys." We had recommended that they build a whole social media - social networking engagement around this particular content that was traditionally printed in books and magazines as well as distributed to partners for their use in a variety of ways.

We found that there was a whole other world of opportunities that had been evolving within this brand - where the consumer was interacting with this brand by delivering their own content or commenting on the content that was out there.

We realized that there was a social networking opportunity alive already within this brand that if developed correctly could possibly develop new markets and increase revenue. Not only with the consumer, but also with their partners.

MM: One of the things that has occurred to me, Dennis, is that a lot of what we know about marketing we know from product marketing. Specifically, durable goods and consumer packaged goods.

One of the breakthroughs for the initial iMac ten years ago was that they used industrial design. The candy-colored bubble. They used industrial design to convey the value proposition of ease-of-use to their primary demographic target: 13-year-old girls.

A lot of what we know about marketing, we know as a function of referencing that aspirational, tribal messaging object that's in your closet or in the driveway.

The challenge that I've been investigating is that oftentimes there's no physical, persistent object that messages your value proposition once you've rendered your service.

However, the overall web property for a service firm has now begun to provide a more persistent messaging and a set of engagements with customers, so as to make the brand deeper and more resonant and more relevant.

DP: Yes. That makes total sense. I think it's something that you and I have talked about quite a bit. It's packaging your IP or your value or what you do. To package it in such a way that the consumer is able to reach out and grab it. They have something on the shelf to remind them of that service again.

That is the challenge for people who are in the services business.

MM: It seems to me that what they want to do is to start to develop an inventory of plush toys with unique identifiers that bring them back to protected premium content areas of a website. That privileges them to have certain kinds of interactions - perhaps with other members of a user community.

DP:Yes. There's a psychology here that has to be addressed. It's the whole personalization model. Everything today is moving toward a very personalized experience. A very directed message to whomever you're trying to engage.

On the services side, that's a lot more challenging. It gets back to that old model. It was successful in some cases, but not in others. That's the case-study model.

If I hear a compelling story and I hear compelling information and results from this story that you're going to tell me, that then engages me into that community and into that world that's been created around that story.

Maybe that's where the future of personalization is for that plush toy for the people in the services market. It's creating these little worlds of personalization that give a very specific message and engage or draw you in 
there. Then you're engaging directly with living case studies. Does that make sense?

MM: It makes complete sense.

DP: Getting back to some of the examples you brought up earlier - let's say that I'm a financial institution trying to target different consumers. I'm not looking to target the big corporate companies. I'm looking to target your common consumers.

Maybe if I enter my profile, I can then get directed to the specific experiences of someone who is my age with my type of salary and whose assets are worth this much and has these kinds of goals. Then I'm targeted to that community.

That community isn't just an offering of "Here are three or four different types of portfolios you can have. By the way, here are also maybe some seminars and some forums and some other groups you can engage in." It's focused specifically on that. Maybe that becomes the whole way of targeting that group and engaging them within the whole social network and social media space.

MM: Marketing must therefore undergo a fundamental transformation.

Now, what's beginning to happen is, social media - blogs and forums and webinars become much more a part of not just the marketing but the actual product management and innovation aspects of a product lifecycle.

One of the things that has resulted in terms of marketing is that marketing is not just about provisioning content, stories, ads and promotions now. It's now begun to provision actual web services.

Marketers now have to start to think through how to deliver online interactive self-services.

Help me think through that whole notion of marketer as provisioner of web services.

DP: Marketers have to do that these days. That's totally where it's going. Again, you brought up some very good points there. As far as companies today going out there in what we call that "ultimate social asset." That's the key piece of content, communication, conversation or whatever you want to call it that exists in this digital space. It allows me to grab that nugget, and that nugget gives me insight into my products. It gives me insight into my services.

It not only engages me with that customer, but it also gives me insights to help me understand what I should do proactively, as opposed to reactively. That's a big part today in what we're seeing out there across all vertical markets.

Grabbing consumers' insights and conversations - to grab that ultimate social asset. Taking that and then creating these engaging experiences.

Basically, present me with the facts. Present me with exactly what I'm going to get. Don't give me the sizzle. I'll take the sizzle if it's going to entertain me. So if you want to make me laugh - fine. But the reality is, if you want to engage me in some kind of entertaining way, I'm okay with that. But you'd better be selling me what you're communicating to me.

Otherwise, I'm not interested in hearing your message again.

Marketers today have to create these engaging experiences for a couple of reasons. One is, it's not only to communicate their products and services. It's also in some nonobtrusive way to gain information and insight about that consumer. To find out a little bit more about them.

It's not just pushing the message. It's finding out a little bit more about them, and doing it in a way that consumers don't feel they're being imposed upon.

You're finding that in many ways today. You're finding it especially in the television ad world. Not to go too far off, but in the whole television ad world you're finding localized broadcasts, now, of commercials. Basically, based on your area code and your location, it determines how those television ads actually get compiled. Then they're able to basically grab key data from those specific area codes and those specific locations to see how effective those marketing campaigns are. There's actually information being gathered from that consumer without that consumer being imposed upon.

You've got to be able to create those engaging experiences where they're able to essentially give information, as well as get it. MM: This then suggests the emerging role of multi-channel marketing analytics. How do I start to go off and either grab, syndicate or convert data into a multi-channel marketing analytic suite so that I really start to develop fact-based insights as far as how to personalize subsequent engagements? 
DP: Right. There are many different names for that. I have a title for that just to keep me focused. I call it a "Global Brand Communications Platform.” That Global Brand Communications Platform is not only about pushing content out. It's also about getting content in and gaining insight on how that content is being used to dynamically deliver content that is relevant to the consumer of it.

The greatest opportunity today for marketers - and for technologists - is to create that analytical layer that allows companies to get immediate insight into what is effective, who needs what, where, when and why, and how quickly we get what they need. So that we can better strengthen our brand perception with the consumers out there.

MM: As we start to develop these much richer and more nuanced analytic profiles - fact-based profiles of consumers - the next thing that seems to emerge as a center of excellence or an area of strategic importance is what I'll call dynamic messaging.

DP: That is absolutely correct.

You're able to grab all of that information. You're able to then personalize that message in the way that I like to hear and see it. That's the other layer. "How do I want to see it?" How do I like to see it? It's also understanding that. What are my mediums of communication? That then can create that dynamic messaging.

MM: This gets into a larger framework, which we call a "media consumption profile." Whereby you specify "I can read. But I'd much rather hear an audio flash explanation in short chunks. My preferred means of learning is, I'm a talkerlistener as opposed to a reader-thinker." DP: That's absolutely correct. That's again a whole other layer of where marketing is going. MM: Right.

With this kind of information, as I set up an account on a website in a member portal or whatever, I'm also not just specifying what product categories I'm interested in, but the means of engagement. For example, "I want things that I can share with my network of friends."

DP: That's right.

MM: As we start to think through this digital supply chain for marketing operations, we've said, "Well, you know, there is some monitoring going on in in the properties that we control - plus our ad network, where we've got paid Google search terms. I'm also monitoring my profiled members in terms of their MySpace page, their FaceBook, their Linked-In. So I understand if there's new information that they're posting on their FaceBook thing, that's now part of their customer profile."

I've got a means of collecting the data. That is, to say syndicating available web data as well as integrating more compiled, refined and enriched data from those information sources. I'm managing it in terms of an analytic process. I am now dynamically personalizing engagements. And now I'm starting to measure the effect of that in terms of if there's any uptick. In terms of downloads of coupons or redemptions of coupons. Store visits. Frequent flyer or member purchase-buyer clubs and that sort of thing.

This gets to, now, a deeper and more challenging set of issues for the CMO. How do I begin to think of and think through the provisioning of services or content without a lot of human intervention? Specifically, from the IT world and IT service management we're getting policy-managed processes.

You then say, "What's a policy?" In that context, we're talking about routing and forms and business rules. So how does a CMO start to think through policy-managed services dynamically provisioned to analytic profiles of stakeholders in our brand?

Take me through that.

DP: Unfortunately, the CMO role is going through a major challenge in transformation. The shelf life today of CMOs I think I heard was 18 months. But that's because I think they're all challenged with this new digital space. MM: In fact, Dennis, isn't the CMO of tomorrow basically a CIO that understands how brand marketing works?

DP: I think it very well could be a melding of the two. There's no question about it. I don't think you can be a successful CMO without having a good technology background. I don't think a CIO that doesn't have good marketing finesse or sensitivity will succeed. I think they'll both be dinosaurs if they don't morph into one.

The CMO of today basically has to be able to first support an execution framework to sustain the vision that they're trying to achieve. That's number one. 
In order to get all of these channels right they really have to begin — in my opinion to get out there and start modeling. Don't try to "boil the ocean." Try to define those ultimate assets in their organization or those "plush toys."

Run them through the entire marketing supply chain. Integrated multi-channel marketing has to be leveraged where it makes sense. Explore all the traditional routes and new media ones, considering and all the different social media and social networking tools and opportunities that are out there. Really begin to start testing that. Create those models with a couple of situations within their brand. If they're a multi-brand company, take one or two of their brands and really just leverage and test all the channels - go whole hog into the social networking and social marketing space. That's the only way to do it, in my opinion. Obviously you need to do thorough analysis. Start small but think big.

A lot of companies out there are investing in all the tools. They're investing in a lot of the technologies. But it's no different now than it was ten or 15 years ago. Companies are spending millions and millions of dollars in technology and spending not enough money on strategic application of those technologies.

Take a couple brands, or a couple products, and figure out how to create working models that successfully leverage that brand across all their traditional and social media channels.

MM: If I understand you right, Dennis, you're advocating basically an $\mathrm{R} \& \mathrm{D}$ project, with the idea of innovating a customer engagement strategy.

DP: That's correct.

MM: Take me through the process of beginning to form that project task force or that team to really put together that research project.

DP: Basically, if we're dealing with an international global company and they've got 12 different divisions. In those divisions, they've got multiple brands.

I would advise the CMO "Let's take this one division here, and let's take these two product lines within this division. Actually, these two brands - not products. We'll take two brands."

We create a multidisciplinary team. That team is made up of key marketing, IT and whatever key business people we need. Maybe the packaging folks, if it's a packaged goods company. All the people that are part of that value chain within that organization.

I'd also include any kind of partners. I'd also include some good strategists in internet marketing and social media space who can provide some guidance there. It would truly be a multidisciplinary team with specific goals and a nimble process so you wouldn't get stuck in a "committee" psychology where nothing gets done.

The next step would be to develop a content strategy. What are the content strategies for each one of the brands? What business goals are we trying to achieve? What is the real market potential? Growth potential? What do we want to do out there on the internet today to be able to engage our customers? What kind of blogging do we need to do? What kind of forums do we need to be a part of? And why do we need to do it? What is the economic justification?

Maybe it's not about creating communities, but about attaching to those communities.

So often, these larger brands especially think they are the world and that the world revolves around them. The reality is, as we know, the world is so much larger than that. Especially with the internet today.

They need to think about "Okay. What communities do I need to start getting involved in? I need to start doing a lot of listening. Who's doing what? How are they doing it?"

Essentially, my focus today is "Let's focus on content strategies for each one of your areas." So if we're talking about just one brand, we're going to have to focus on what all of your content strategies are - both social mediarelated as well as traditional media-related. We're going to cultivate those first.

The team's first approach is to do that. It's to go out there and to begin to engage. They need to listen. I would.

Let me see if I can illustrate the model, or framework, a bit differently.

The first step is to establish the teams. Right? That's something that's so often neglected. There's got to be a lot of careful consideration of who's part of that team.

I always say the first part of that team is the executive advisory team. I hate using the word, "Committees." Committees just have such a negative feel to them. 
The executive advisory team is key. That team is very instrumental in developing the framework of operations and defining strategies and expectations. They need to make sure that the framework is in place to support the initiatives across the enterprise.

Any company that's going to engage in this kind of effort has to have the support at the highest levels. Why? Because it's disruptive. You're going to cause disruption throughout the entire culture of your business. And the only way you're going to get the support to do that and be successful at it is if you have support at the highest level.

The first part is putting together that executive advisory team. The CMO has to be at the head of that group, or has to have a very strong designee that's leading that group.

The next group that's part of that is your implementation team. That team is actually going to implement whatever you're going to do in this first phase.

Another key pillar there is what I call developing the business and technology model. Whether you're sourcing one brand or two brands or whatever works - whatever makes sense in your particular environment. You're going to develop business and technology models.

Part of those business and technology models - again - whether you're dealing in the social media space or the traditional media space... You're going to define those content strategies.

Another key part is your best practices particularly your online marketing best practices. You're going to spend time defining what those marketing best practices are. That will then lead to your search optimization modeling and how you define your taxonomy and vocabulary standardization.

Now, how do I optimize my workflow to remove all these unnecessary overheads that I may not even be aware of? I'm not going to implement any kind of technology solution on top of dysfunctional ways of working.

MM: For example, Dennis - a company might have an online group that's a completely rogue maverick group that's part of the overall marcom. They don't really report into marcom and they don't really share assets. They're off doing their e-commerce or their online thing.
That would be an example of something that would have to be reintegrated back into more of a coherent marketing content strategy. Did I get that right?

DP: Perfect. Perfect example. Especially for global Fortune 500s. It's so common. It's amazing to me how there is a lack of sensitivity to that. You cannot have a global brand communications platform to leverage content via multiple channels without being able to at least centralize a lot of the way content is managed.

MM: Another area we've run across has been this notion of localization centers.

DP: That's right. That's huge. I can certainly speak to that. I have some good experience with that. In fact, I'm working on a project right now with a healthcare company that needs to deliver localized content both online and in print.

In the past, I worked with one of the automotive manufacturers where online interactions initiated offline marketing materials. It was basically a web-to-print initiative with print-on-demand capabilities for personalization and better management of print marketing costs. How you built your vehicle determined what materials you received in the mail. The printed material was the red minivan - the interior you'd selected - and it was personalized, printed material. You kept your printing costs down because you were only printing what you needed but more importantly you were able to get insight as to what models and colors people were searching on to help manage future production.

Maybe you selected a red, minivan, gray interior and specific options. You typed in your zip code and other key data and we collected all of the data. And the longer the interactions, especially after the transactions, the more data we collected. Ultimately we wanted to get you into a loyalty program.

MM: Another thing, Dennis. That's this notion of what I'll call "The end of campaigns as we know them."

If you think about campaigns - campaigns really kind of reflect a flat-world 1.0 kind of world framework. That is to say, I've got this insight and I've validated it with some customer research. Some focus groups. Maybe some survey research. I've put together a strategy to execute 
on that insight. I've put together my marketing brief and my creative brief. I've got all of my agencies running around executing their respective creative briefs.

The problem today is that it's no longer enough simply to start six months ago with insights. I've got to execute a campaign virtually every day.

So all of a sudden the whole mindset - the whole mental framework of a campaign begins to implode. It begins to simply no longer function because it's no longer a linear process. It's a 360-degree omni-directional brand interaction. And these brand interactions tend to evolve through a maturity lifecycle for the brand as it lives in the customer.

DP: That's absolutely correct. The reality is that brands have to use the 360-degree model and get away from the traditional linear marketing approach.

MM: As it relates to marketing operations management, how does this change things? DP: It's going to have an effect there as well. The reality is that marketers have to get into that 360-degree mentality. They've got to get into thinking about how to dynamically manage campaigns.

Maybe not all of the campaigns, but a larger percentage of that campaign is going to have to be managed dynamically. That is then reciprocally — going to effect how marketing operations and management are done effectively.

MM: That's my point, Dennis. It's not a campaign any more. It's an engagement. DP: That's right. It's a continuum, too. It just continues. It's an engagement that is dynamic. It's alive.

Marketers have traditionally driven so hard to a date. So hard to meet a date and deadline. That's gone. The new company - the new marketer - gets that managing the relationship is much more important than managing the campaign. Before managing the customer was more of an ideal: today is the reality of effective marketing. That is a major transformation that's happening today.

MM: Maybe now what we need to look at is more of a suite of tools. Right? For the marketing operations. We're no longer thinking in terms of campaign management. We're really now needing to think in terms of engagement management.
Upstream, the part of engagement management is the whole multi-channel marketing analytics — what's going on out there.

The other piece of this whole engagement management is now scheduling. Scheduling not only staff internally, but a whole network of contractors and agencies and partners.

Scheduling looms even larger and more strategic than project management.

The big area of innovation - both in terms of technical innovation and process innovation - is the interplay. The feedback loops between this multi-[inaudible] and engagement. That then starts to define the new core practices and technologies and disciplines of the effective marketing operations.

DP: That's correct. Really simple. The technology has to be nimble. And more importantly, the processes of how people work have to be as well. That's it.

That is such a bulldozer through so many companies today.

MM: Could you speak to this notion of a services framework?

DP: I think the services framework is becoming a big reality in our world today. It is the foundation of initiatives we've talked about. When you talk about "buy versus build," today it's becoming more and more practical in many cases to go out and buy it as opposed to build it.

You're seeing a big shift in companies there, and it's very difficult psychologically for companies to get over that. But you're seeing a lot of momentum there - in regard to "buying" chunks of their software and infrastructure.

Some of these frameworks are made up of multiple components. Some of them being bought and some of them being built. Today there is a shift, even in large traditional corporations, to buying instead of building. In the internet world you talk about white labeling. There are white label solutions out there that are much more cost-effective to buy than they are to build. It saves time and money and a company can ramp up quickly and get exactly what they need within a very fast period. It allows internet businesses to be born pretty much overnight.

MM: On a concluding note, it's probably pretty important for the vice-president of marketing 
operations, if not the $\mathrm{CMO}$, to define and own that services framework.

DP: They have to own it. There's no question about the fact that the $\mathrm{CMO}$ or his or her designee have got to own this services framework. They have to be partnered with a good IS group that is able to be very close in line with them and deliver cost-effectively what they need to support the business initiatives. MM: Not just the IS group, but this new crop of agencies that are emerging - which are essentially digital brand interaction platforms with subject-matter expertise, analytics and deep technical capabilities in one or two brand interactions.

DP: Sure. There's a whole "ecosystem" out there - a digital supply chain. And when it comes to
IT, your traditional IT department needs to be dismantled in the way it thinks and behaves.

Some of us saw this coming in the early 1990s. We knew that IT in the future was about specialists closely aligned with the business, and at the senior levels there existing no distinction between IT and non-IT. If you really wanted to climb the ladder over the long term, it was really about these "specialists" who were business-oriented and brought technical experience and savvy to stand out in front.

That's kind of full-circle to what you and I talked about earlier on - this merging of a CMO and CIO. That's exactly what we're seeing in demand today.

MM: I want to thank you very much, Dennis. 